\title{
Hematological and inflammatory parameters in hospitalized patients with COVID-19 infection in Chattogram, Bangladesh
}

\author{
Md. Rakibul Hassan BULBUL 1, a (D), Md. Giash UDDIN 2, 3, a (D), Kazi Ishrak FAIYAZ 4 (D), \\ Mohammad Rashedul ISLAM 2 (D), Md. Ashraful ALAM 2 (D), Shakeel AHMED 4 (D), \\ Md Zakir HOSSAIN 4 (D), Mohammed LOKMAN 4 (D), Mohammad Safiqul ISLAM 5, * iD \\ 1 Institute for Developing Science and Health Initiatives (ideSHi), Dhaka-1212, Bangladesh. \\ 2 Department of Pharmacy, University of Chittagong, Chittagong-4331, Bangladesh. \\ 3 Pratyasha Health Biomedical Research Center, Dhaka-1230, Bangladesh. \\ 4 Bangladesh Institute of Tropical and Infectious Diseases (BITID), Chittagong-4317, Bangladesh. \\ 5 Department of Pharmacy, Noakhali Science and Technology University, Noakhali-3814, Bangladesh. \\ a These authors contributed equally. \\ * Corresponding Author. E-mail: research_safiq@yahoo.com (M.S.I); Tel. +880-172-765 8650.
}

Received: 01 July 2021/ Revised: 16 August 2021/ Accepted: 27 August 2021

\begin{abstract}
COVID-19 emerged as a pandemic that is persisting with massive casualties around the globe. To ensure clinical management, changes in hematological parameters are routinely monitored and considered essential in patients with coronavirus disease 2019 (COVID-19) to measure the disease prognosis. This study aimed to recognize alterations in patients' hematological and inflammatory parameters with COVID-19. We obtained and analyzed data from 170 COVID-19 positive patients and 78 COVID-19 negative patients confirmed by qRT-PCR. The laboratory data included the hematological and inflammatory parameters of the selected patients. Compared with COVID-19 negative groups, COVID-19 patients had significantly higher levels of hematocrit $(\mathrm{HCT})(\mathrm{p}<0.01)$, mean platelets volume $(\mathrm{MPV})(\mathrm{p}$ $<0.01)$, neutrophils $(\mathrm{p}<0.01)$, erythrocyte sedimentation rate $(E S R)(p<0.0001), C$-Reactive Protein $(C R P)(p<0.0001)$, and significantly lower levels of Hemoglobin $(\mathrm{Hb})(\mathrm{p}<0.0001)$, lymphocytes $(\mathrm{p}<0.0001)$, monocytes $(p<0.0001)$, eosinophils $(\mathrm{p}<0.01)$, basophils ( $\mathrm{p}<0.05)$. This study also observed significantly increased levels of $\mathrm{Hb}, \mathrm{HCT}, \mathrm{RBC}$, $\mathrm{MCH}, \mathrm{MCHC}$, monocytes, ferritin, and significantly decreased RDW-CV, platelets count, ESR in the COVID-19 male patients than the COVID-19 female patients. This study suggests that hematological and inflammatory parameters should be considered in the clinical management of COVID-19 patients.
\end{abstract}

KEYWORDS: COVID-19; hematological parameters; inflammatory parameters; clinical features; Bangladesh.

\section{INTRODUCTION}

Infectious diseases are responsible for massive public health casualties all over the world. A myriad of underlying factors contribute to disease, most generally involving human behavior [1]. A growing infectious disease causes rapid spread and needs urgent action to avoid the illness at the grassroots level [2]. The new coronavirus was initially an unrevealed sign of pneumonia but epidemiologically linked to a seafood market at the Hubei Province of Wuhan, China [3]. Then, it was identified as a novel coronavirus named severe acute respiratory syndrome coronavirus 2 (SARS-CoV-2) [4,5]. This virus belongs to $\beta$-coronavirus, a broad class of single-stranded RNA viruses dominant in nature that can affect both animals and humans and can initiate respiratory, hepatic, gastrointestinal, and neurologic disorders [6,7].

The local outbreak has already been largely contained, although the latest coronavirus is spreading rapidly in other areas across the globe [8,9]. World Health Organization (WHO) declared this new outbreak of pneumonia as a global pandemic. The common symptoms include sore throat, cough, malaise, fever, diarrhea, breathing difficulties. In severe cases, pneumonia, organ failure, severe acute respiratory syndrome, and death occur, especially for patients with elderly and multiple disorders [10]. Usually, infection is transmitted by symptomatic and asymptomatic patients via large droplets produced during coughing and

How to cite this article: Bulbul MRH, Uddin MG, Faiyaz KI, Islam MR, Alam MA, Ahmed S, Hossain MZ, Lokman M, Islam MS. Hematological and inflammatory parameters in hospitalized patients with COVID-19 infection in Chattogram, Bangladesh. J Res Pharm. 2021; 25(6): 857-865. 
sneezing $[11,12]$. Approximately $20 \%$ of patients with COVID-19 turn out critically ill, with elevated mortality ranging from $8.1 \%$ to $33 \%$ [13].

Blood tests provide valuable information to physicians regarding the inflammatory process in COVID19 cases. Other info comprises leukocyte count and features such as neutrophil or lymphocyte dominance, inflammation (C-reactive protein), and concurrent organ impairment (acute renal failure, acute liver failure). These parameters can differentiate between viral (pneumonia) and bacterial infection during detection [14]. The analysis of CBC (complete blood counts) can be done quickly and is a cheap process. The parameters included in this analysis are white blood count, lymphocyte, neutrophil, and PLT (platelet count), mean platelet volume, and set of ratios of these values [15]. These are marked as inflammatory markers and neutrophils among the white blood cells recognized as the vital immune system element. Neutrophils may have interaction or cross-talk with these other associated immune cells.

Several findings reported that increased D-dimer and decreased platelet count are a reflection or markers of disease severity [16,17]. In comparison to the regular group, several studies frequently mentioned that patients with severe and critical conditions showed significant low lymphocyte count, eosinophil, decreased red blood cell and hemoglobin count, significantly higher in white blood cell count, neutrophil count, interleukin-6, procalcitonin, erythrocyte sedimentation rate, C-reactive protein, D-dimer, fibrinogen, ferritin, and lactate dehydrogenase [18-20].

In this present study, we have analyzed the clinical data of 170 COVID-19 cases confirmed by qRT-PCR belongs to Bangladeshi populations. So, the prime objective of this study is to deliver insights into the furbish laboratory features of the patients with this disease and to improve outcomes.

\section{RESULTS}

\subsection{Basic characteristics of the patients}

Among the 170 patients, 113 (62.78\%) were males, and 57 (37.22\%) were females. In the COVID-19 negative patients, $43(55.13 \%)$ were males, and $35(44.87 \%)$ were females. The patients' average age was 49.55 years, and the average age of the COVID-19 negative patients was 51.65 years. There was no significant difference in age between the two groups. The critical clinical manifestations were the patient's fever, cough, sore throat, shortness of breath, diarrhea, myalgia or arthralgia, no smell or taste, and headache. Coexisting disorders, diabetes, hypertension, renal disease, liver disease, and COPD were the most common in patients and COVID-19 negative patients. (Table 1).

Table 1. Clinical characteristic of the patients.

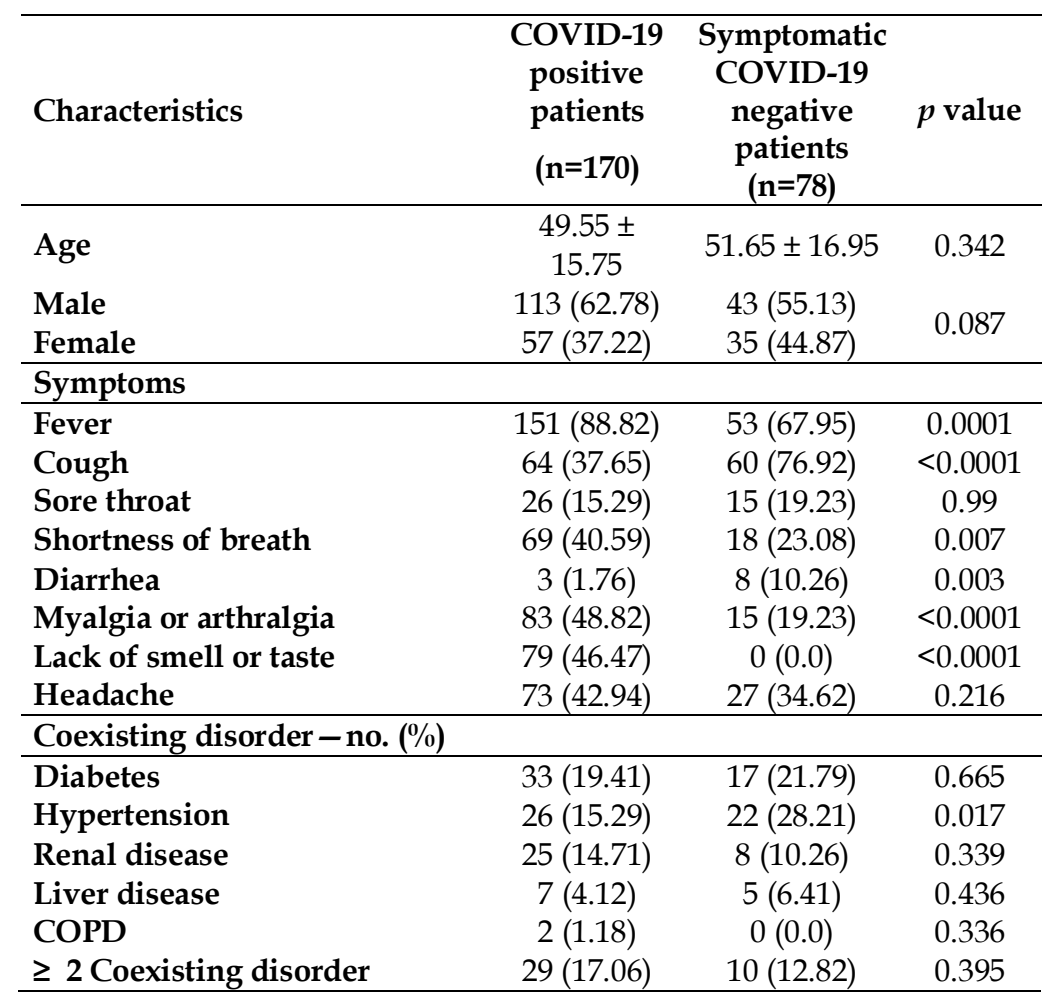




\subsection{Hematological parameters}

The results found that $\mathrm{Hb}$ and $\mathrm{HCT}$ level was significantly reduced in the patient's group than the COVID-19 negative patients. It also found that RBC, MCV, MCH, RDW-SD were mainly in the normal reference range. Normal ranges of hematological parameters in both males and females are shown in Table S1. There was a slight increase in MCHC and RDW-CV levels in the patient's group than the COVID-19 negative patients $(\mathrm{p}<0.0001$ and $\mathrm{p}>0.05$, respectively). The platelet count and the mean platelet volume were mainly in the normal reference range. The neutrophils, lymphocytes, monocytes, eosinophils, and basophils levels were in the normal reference range. But there was a decrease in lymphocyte, monocytes, eosinophils, and basophils levels in the patient group than the COVID-19 negative patients was observed. (Table 2).

Table 2. Comparisons of hematological parameters between patients.

\begin{tabular}{lccc}
\hline Parameters & $\begin{array}{c}\text { COVID-19 } \\
\text { positive patients } \\
\text { (n=170) }\end{array}$ & $\begin{array}{c}\text { Symptomatic } \\
\text { COVID-19 } \\
\text { negative } \\
\text { patients (n=78) }\end{array}$ & p value \\
\hline Complete blood count & $12.39 \pm 1.72$ & $13.45 \pm 2.15$ & $<0.0001$ \\
\hline Hb (gm/dL) & $39.37 \pm 4.98$ & $36.96 \pm 6.46$ & 0.002 \\
HCT (\%) & $4.44 \pm 0.63$ & $4.54 \pm 0.71$ & 0.241 \\
RBC (10^12/L) & $86.83 \pm 55.23$ & $83.09 \pm 9.04$ & 0.553 \\
MCV (fL) & $27.50 \pm 2.96$ & $27.77 \pm 1.62$ & 0.447 \\
MCH (pg) & $33.04 \pm 1.29$ & $32.33 \pm 1.41$ & $<0.0001$ \\
MCHC (g/dL) & $14.18 \pm 2.09$ & $14.23 \pm 1.66$ & 0.831 \\
RDW-CV (\%) & $42.25 \pm 5.95$ & $41.73 \pm 4.48$ & 0.488 \\
RDW-SD (fL) & & & \\
\hline Platelet & $232.05 \pm 81.87$ & $237.73 \pm 74.95$ & 0.603 \\
\hline Platelets count (10^9/L) & $10.39 \pm 1.58$ & $9.69 \pm 1.42$ & 0.001 \\
Mean platelet volume (fL) & & & \\
\hline Absolute leukocyte count & $4.61 \pm 2.90$ & $3.40 \pm 1.68$ & 0.001 \\
\hline Neutrophils (10^9/L) & $1.34 \pm 0.53$ & $1.84 \pm 1.11$ & $<0.0001$ \\
Lymphocytes (10^9/L) & $0.53 \pm 0.22$ & $0.70 \pm 0.37$ & $<0.0001$ \\
Monocytes (10^9/L) & $0.09 \pm 0.15$ & $0.18 \pm 0.31$ & 0.002 \\
Eosinophils (10^9/L) & $0.02 \pm 0.02$ & $0.03 \pm 0.08$ & 0.040 \\
Basophils (10^9/L) & & & \\
\hline
\end{tabular}

\subsection{Inflammatory biomarkers}

The levels of erythrocyte sedimentation rate (ESR), D dimer, ferritin, creatinine, C-reactive protein (CRP), and procalcitonin in patients rose in varying degrees. The ESR and CRP level was significantly different in patients and COVID-19 negative patients. (Table 3). Normal ranges of inflammatory biomarkers in both males and females are shown in Table S1, which represents the data of the healthy ones.

\section{DISCUSSION}

After the rhinoviruses, coronavirus infections have been deemed the second most leading cause to afflict people with the common cold. While researchers have corroborated the fact that SARS-CoV-2 possesses all the criteria as coronavirus, it has also recently been divulged that the binding potentiality of SARS-CoV-2 to ACE2 receptor in vivo is higher than that of SARS-CoV by 10-20 folds, rendering it more contagious than ever, which eventually leads to a global pandemic [21]. The clinical manifestations shown by COVID-19 patients have been reported as large pyrexia, fatigue, and dry cough [13,22]. In this study, we observed the clinical symptoms manifested by 170 COVID-19 patients. Here the laboratory analysis of COVID-19 patients, particularly hematological and inflammatory parameters, was primarily analyzed and summarized. 
Table 3. Comparisons of inflammatory biomarkers between patients.

\begin{tabular}{lccc}
\hline Parameters & $\begin{array}{c}\text { COVID-19 } \\
\text { positive patient } \\
(\mathbf{n = 1 7 0 )}\end{array}$ & $\begin{array}{c}\text { Symptomatic COVID-19 } \\
\text { negative patients (n=78) }\end{array}$ & $\boldsymbol{p}$ value \\
\hline & $26.88 \pm 23.45$ & $12.31 \pm 5.24$ & $<0.0001$ \\
ESR $(\mathrm{mm})$ & $0.59 \pm 1.95$ & $0.34 \pm 0.16$ & 0.249 \\
D Dimer $(\mathrm{ug} / \mathrm{mL})$ & $288.69 \pm 421.65$ & $217.91 \pm 136.31$ & 0.149 \\
Ferritin $(\mathrm{ng} / \mathrm{mL})$ & $1.55 \pm 8.30$ & $1.13 \pm 1.40$ & 0.652 \\
Creatinine $(\mathrm{mg} / \mathrm{dL})$ & $29.76 \pm 43.76$ & $6.16 \pm 3.64$ & $<0.0001$ \\
C- Reactive Protein $(\mathrm{mg} / \mathrm{L})$ & $0.18 \pm 0.58$ & $0.10 \pm 0.13$ & 0.273 \\
Procalcitonin $(\mathrm{ng} / \mathrm{mL})$ & & & \\
\hline
\end{tabular}

Table S1. Normal ranges of hematological parameters.

\begin{tabular}{lcc}
\hline Parameters & Male & Female \\
\hline Complete blood count & & \\
\hline $\mathrm{Hb}(\mathrm{gm} / \mathrm{dL})$ & $13.0-17.0$ & $12.0-15.0$ \\
$\mathrm{HCT}(\%)$ & $40-50$ & $36-46$ \\
$\mathrm{RBC}\left(10^{\wedge} 12 / \mathrm{L}\right)$ & $5.0-7.0$ & $3.8-4.8$ \\
$\mathrm{MCV}(\mathrm{fL})$ & $83-101$ & $83-101$ \\
$\mathrm{MCH}(\mathrm{pg})$ & $27-32$ & $27-32$ \\
$\mathrm{MCHC}(\mathrm{g} / \mathrm{dL})$ & $27-32$ & $27-32$ \\
$\mathrm{RDW}-\mathrm{CV}(\%)$ & $11.6-14.0$ & $11.6-14.0$ \\
$\mathrm{RDW}-\mathrm{SD}(\mathrm{fL})$ & $39-46$ & $39-46$ \\
\hline Platelet & & \\
\hline Platelets count $\left(10^{\wedge} 9 / \mathrm{L}\right)$ & $150-450$ & $150-450$ \\
Mean platelet volume (fL) & $6.5-12.0$ & $6.5-12.0$ \\
\hline Absolute leukocyte count & & \\
\hline Neutrophils $\left(10^{\wedge} 9 / \mathrm{L}\right)$ & $2.0-7.0$ & $2.0-7.0$ \\
Lymphocytes (10^9/L) & $1.0-3.0$ & $1.0-3.0$ \\
Monocytes (10^9/L) & $0.2-1.0$ & $0.2-1.0$ \\
Eosinophils $\left(10^{\wedge} 9 / \mathrm{L}\right)$ & $0.02-0.5$ & $0.02-0.5$ \\
Basophils (10^9/L) & $0.02-0.1$ & $0.02-0.1$ \\
\hline
\end{tabular}

The most prevalent symptoms spotted were fever $(n=146)$, cough $(n=151)$, myalgia $(n=83)$, absence of smell or taste $(n=79)$, headache $(n=73)$, dyspnea or shortness of breath $(n=69)$, cough $(n=64)$, and sore throat $(\mathrm{n}=26)$, whereas only less than $2 \%$ patients had diarrhea. Many comprehensive studies have also reported the same symptoms involved with COVID-19 patients [18,19,23].

In the COVID-19 groups, we found that a lower $\mathrm{Hb}$ level was linked to a more severe disease course and a higher mortality rate. This drop-in $\mathrm{Hb}$ level can be attributed to the inflammation related to COVID-19. In acute inflammation, a decline in the $\mathrm{Hb}$ level is anticipated due to numerous intricate mechanisms. The best known among these is inhibition of Epo formation and cytokines-induced iron metabolism dysregulation [24]. We also juxtaposed the hematological parameters between two gender groups of COVID-19 patients. We concluded that male patients had experienced a significant rise in $\mathrm{Hb}$ levels compared to their female counterparts. Lower iron stores in premenopausal females may be responsible for lower $\mathrm{Hb}$ levels and are unlikely from COVID-19.

In addition to that, a complete blood count investigation revealed the alteration of $\mathrm{HCT}, \mathrm{RBC}, \mathrm{MCV}$, $\mathrm{MCH}, \mathrm{MCHC}$, RDW-CV, RDW-SD levels between the two cohorts with the following respective P -values: ( $\mathrm{P}=0.002 ; \mathrm{P}=0.241 ; \mathrm{P}=0.553 ; \mathrm{P}=0.447 ; \mathrm{P}=<0.0001 ; \mathrm{P}=0.831$, and $\mathrm{P}=0.488$ ). $\mathrm{HCT}$, RBC, or anemias seen in patients with comorbidities are explained by the bone marrow's incapability to engender adequate RBCs to transport oxygen. The lung injuries impaired by COVID-19, which in turn makes gaseous exchange way more complicated. On the one hand, these abnormalities could elucidate dyspnea symptoms in the present study population. But, comorbid conditions current in these patients might also intervene with RBC synthesis due to the existing inflammation [23]. Although male patients underwent a marked increase in HCT, RBC, MCH, MCHC levels, and a substantial decrease in RDW-CV level than their female counterparts (Figure 1), no significant disparity was noted in MCV, RDW-SD levels between male patients and female patients when compared (Figure 1). In females, it is also likely some of the recruited female patients had iron deficiency (red cell parameters reflect this), given that the median age was 57 with a standard deviation of 37.22 years, suggestive that there were pre-menopausal women within the recruited group. 

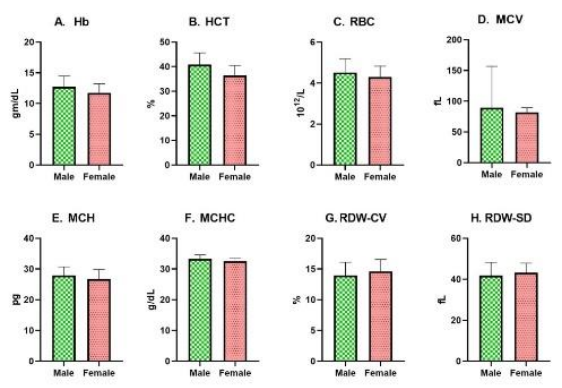

Figure 1. Comparison of $\mathrm{CBC}$ between male and female patients; Hb: hemoglobin, HCT: hematocrit, RBC: red blood cell, MCV: mean cormpuscular volume, $\mathrm{MCH}$ : mean corpuscular hemoglobin, $\mathrm{MCHC}$ : mean corpuscular hemoglobin concentration.

Usually, the thrombocytopenic events increase with the severity of disease in COVID-19 patients [25]. Diminished platelet count, which surrogates their expenditure and thrombin formation, helps detect coagulopathy's presence and intensity. Thrombocytopenia, commonly present in viral infections, could be expounded by impaired megakaryopoiesis, inappropriate activation and consumption of platelet, and immunological platelet destruction [26]. Having stated that, it is unknown whether the mechanisms of thrombocytopenia vary between SARS-CoV-2 and other types of coronaviruses [18]. The female patients were found to have an escalated level of platelet count and a lower level of MPV compared to their male companions (Figure 2).

As the knowledge about COVID-19 extends lymphocyte function tests, and inflammatory factors have been advocated for appraising the severity of the disease [27]. Not all the tests can readily be accessed, though. Our results underscored that the high neutrophil to lymphocyte ratio, which might arise due to immune suppression and exceeding inflammation in sepsis-induced by SARS-CoV-2 infection, can be used to foretell the extent of severity and mortality. Moreover, routine blood tests are immediately available, and the neutrophil to lymphocyte ratio can be computed efficiently. In sepsis, neutrophils are overly aroused with delayed apoptosis disorder, together with the exhaustion and depletion of CD4 and CD8 T cells driven by apoptosis [28], commonly in severe cases of COVID-19 [29]. In contrast to tests that are somewhat less available, the neutrophil to lymphocyte ratio provides the impression of being a useful and valuable marker to assess the mortality risk associated with COVID-19. All of these coronavirus families named SARS-CoV, MERS-CoV, and SARS-CoV-2 have been affirmed to cause lymphocytic depletion in patients with infection $[30,31]$, and the underlying mechanism could presumably be happened by the direct invasion of the virus on lymphocytes or due to the immune-mediated apoptosis of lymphocytes [32-34]. In this study, we figured out that the lymphocyte count in the peripheral blood circulation of COVID-19 patients declined to different extents, albeit the causes of why SARS-CoV-2 gives rise to lymphocytopenia in the patient is not explicit up to date. Our study also managed to observe greater monocytes level in male patients contrasting to the female patient group. However, as mentioned earlier, no statistically significant discrepancy was perceived regarding neutrophils, lymphocytes, eosinophil, and basophil levels between the genders (Figure 3).

While carrying out this present study, a heightened D-dimer content in the patient's group had come into our views than the COVID-19 negative patients. Previous studies have also reported that a markedly elevated D-dimer amount is commonly evident in deaths with COVID-19 [19,35]. Based on these results, it is proposed that the D-dimer levels might potentiality assess prognosis and guide treatment.

Procalcitonin and CRP, two common biomarkers, can be secreted during the acute phase of the systemic inflammatory response [36,37]. Procalcitonin levels usually elevate mildly in viral infection, whereas significant elevation is seen in fungal, bacterial, or parasitic infections [38]. CRP is a generally helpful marker of the systemic inflammatory response [39,40]. Ferritin, which is regarded as a critical mediator in immune dysregulation, is linked to cytokine storm syndrome if present in excess. Raised ferritin level has been reported by several studies in COVID-19 patients [9,41]. Enhanced plasma creatinine values can act as an indicator of reduced excretion. The Guidelines on COVID-19 by the International Federation of Clinical Chemistry and Laboratory Medicine (IFFC) strongly urge monitoring of creatinine in COVID-19 patients to detect kidney injury [42]. The development of acute kidney injury (AKI) and its association with mortality have also been clarified for the erstwhile coronaviruses causing SARS (severe acute respiratory syndrome) and MARS (Middle East respiratory syndrome) [43,44]. Our study was capable of confirming the ESR, ferritin, Creatinine, $\mathrm{CRP}$, and procalcitonin to be higher in the patients' group against the COVID-19 negative patients, implying that the inflammatory response was noticeably more evident in patients with a severe form of COVID-19. We also measured an increased D-dimer level, ferritin, CRP, and procalcitonin, but a decreased level of ESR and Creatinine in male patients than the female ones (Figure 4). 

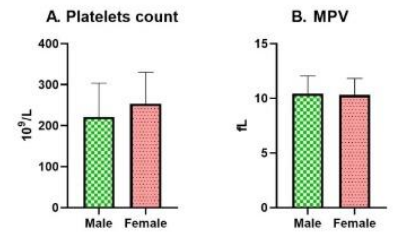

Figure 2. Comparison of platelets between male and female patients; MPV: mean platelet volume.

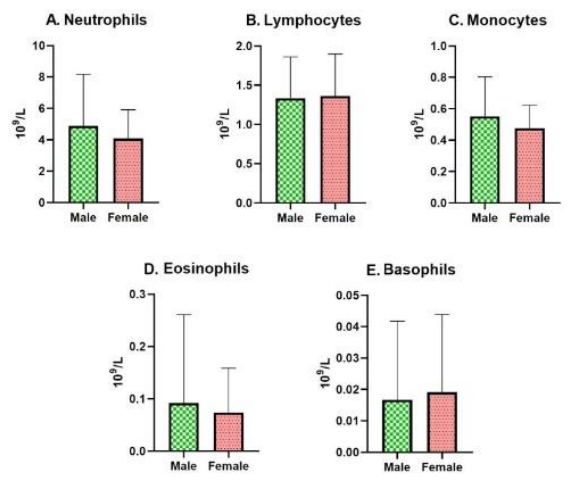

Figure 3. Comparison of leukocytes between male and female patients.
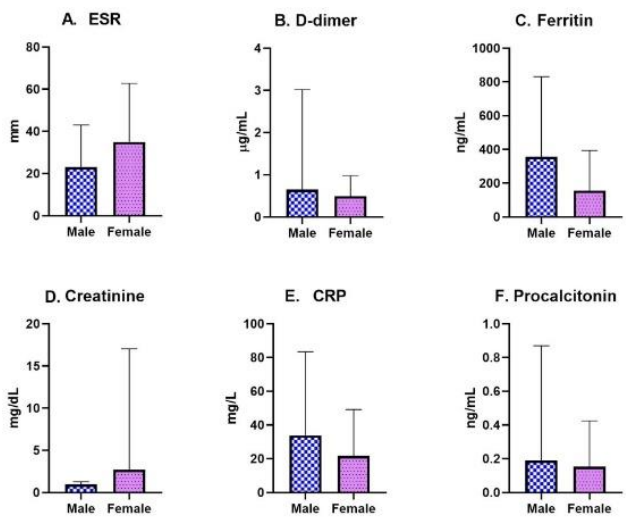

Figure 4. Comparison of inflammatory parameters between male and female patients; ESR: erythrocyte sedimentation rate, CRP: c-reactive protein.

There is no study regarding the hematological and inflammatory parameters of COVID-19 patients from Bangladesh. Although some previous studies conducted almost similar research, our study presented all the hematological and inflammatory parameters in a single study. The most noticeable shortcoming of the current study was the lack of a sufficient number of patients. Studies with a relatively larger sample size would be better delineate clinically significant peripheral blood biomarkers to diagnose COVID-19 patients. Additionally, the patient data's dynamic collection was not comprehensive, and the impact of alterations in immunological \& hematological indicators on the patient's disease prognosis could not be analyzed. Finally, patients' lifestyles, including their habits (i.e., alcohol consumption and cigarette smoking), were not adequately garnered from the patient files. Their influences on the results were also not considered.

\section{CONCLUSION}

In summary, our study observed the alteration of hematological and inflammatory parameters in COVID-19 patients. Compared to COVID-19 negative groups, in COVID-19 patients, the levels of Hb, RBC, $\mathrm{MCH}$, RDW-CV, platelets count, lymphocytes, monocytes, eosinophil, and basophils were decreased, whereas $\mathrm{HCT}, \mathrm{MCV}, \mathrm{MCHC}$, RDW-SD, mean platelet volume, neutrophils, ESR, D-dimer, ferritin, creatinine, CRP, and procalcitonin were increased. This study also observed significantly increased levels of $\mathrm{Hb}, \mathrm{HCT}, \mathrm{RBC}, \mathrm{MCH}$, $\mathrm{MCHC}$, monocytes, and ferritin, whereas significantly reduced levels of RDW-CV, platelets count, and ESR were observed in male COVID-19 patients than the female COVID-19 patients. Therefore the parameters referred to above should be paid careful attention to in the clinical management of COVID-19 patients. 


\section{MATERIALS AND METHODS}

\subsection{Study design and study sites}

The case-control study was performed among the COVID-19 cases confirmed by qRT-PCR of ORF-1ab and N genes assay seeking medical care in Bangladesh Institute of Tropical and Infectious Diseases (BITID), Chattogram, from October 2020 to December 2020. The Ministry of Health and Family Welfare (MOHFW) of Bangladesh defined the proposed selection criteria of possible COVID-19 patients. Patients that have at least one indication or symptom of fever or acute respiratory illness, or clinical characteristics that are inexplicable by any other disease, or a history of travel to another country in the previous 14 days before the occurrence of symptoms in the patient or a family, or near contact with a patient-reported positive for COVID-19, meet these criteria. No additional tests were conducted on these patients after the initial qRT-PCR and CBC findings were used. A biochemistry specialist examined and accepted the CBC findings obtained from this study.

\subsection{Sample size \& data collection}

A total of 170 COVID-19 positive patients and 78 COVID-19 negative patients were recruited for this study. In this study, COVID-19 positive patients were used as cases, and COVID-19 negative patients were used as control groups. As the key sources of data, a related questionnaire and patient history were taken into consideration. Hospital reports were also checked in terms of data, and the history of any other coexisting condition was gathered by self-reporting and also records. All retrospective data were gathered from patient's medical file and recorded in electronic form. All information counted in this study was double-checked, submitted, and the records were preserved.

\subsection{Inclusion \& exclusion criteria}

Only patients above the age of 18 years were included in the study. Both cases and controls confirmed by qRT-PCR using nasopharyngeal swabs were included in the study. The patients who had severe respiratory distress requiring intensive care support and patients with an incomplete diagnosis for hematological and inflammatory features were excluded from this study.

\subsection{Ethical consideration}

This study was followed the principles of the Declaration of Helsinki of the World Medical Association. Ethical permission was obtained from the ethical committee of Noakhali Science and Technology University (ID-39/2020).

\subsection{Statistical analysis}

All the values were expressed as the mean \pm SD. Between COVID-19 positive and COVID-19 negative patients, independent sample t-tests were performed. All analyses were carried out using SPSS Statistics 25 (IBM, Armonk, New York).

Acknowledgements: The authors are thankful to Bangladesh Institute of Tropical and Infectious Diseases (BITID) and ethical approval committee of Noakhali Science and Technology University.

Author contributions: Concept - M.R.H.B., M.G.U.; Design -M.R.H.B., M.G.U, K.I.F.; Supervision - M.S.I., S.A.; Resources - M.R.I., M.A.A., S.A., M.S.I.; Materials -K.I.F., M.Z.H., M.L.; Data Collection and/or Processing - M.Z.H., M.L.; Analysis and/or Interpretation -M.G.U., M.R.H.B., K.I.F.; Literature Search - M.R.I., K.I.F.; Writing -M.G.U., M.A.A., M.R.I.; Critical Reviews - M.R.H.B., M.G.U., K.I.F., M.R.I., M.A.A., S.A., M.Z.H., M.L., M.S.I.

Conflict of interest statement: The authors declared no conflict of interest.

Ethics committee approval: This study was followed the principles of the Declaration of Helsinki of the World Medical Association. Ethical permission was obtained from the ethical committee of Noakhali Science and Technology University (ID-39/2020).

\section{REFERENCES}

[1] Watkins K. Emerging Infectious Diseases: a Review. Curr Emerg Hosp Med Rep. 2018; 6: 86-93. [CrossRef]

[2] Lin L, McCloud RF, Bigman CA, Viswanath K. Tuning in and catching on? Examining the relationship between pandemic communication and awareness and knowledge of MERS in the USA. J Public Heal (United Kingdom). 2017; 39: 282-289. [CrossRef] 
[3] Zhu N, Zhang D, Wang W, Li X, Yang B, Song J, et al. A Novel Coronavirus from Patients with Pneumonia in China, 2019. N Engl J Med. 2020; 382: 727-733. [CrossRef]

[4] Wang L, Wang Y, Ye D, Liu Q. Review of the 2019 novel coronavirus (SARS-CoV-2) based on current evidence. Int J Antimicrob Agents. 2020; 55: 105948. [CrossRef]

[5] Li Q, Guan X, Wu P, Wang X, Zhou L, Tong Y, et al. Early Transmission Dynamics in Wuhan, China, of Novel Coronavirus-Infected Pneumonia. N Engl J Med. 2020; 382: 1199-1207. [CrossRef]

[6] Andersen KG, Rambaut A, Lipkin WI, Holmes EC, Garry RF. The proximal origin of SARS-CoV-2. Nat Med. 2020; 26: 450-452. [CrossRef]

[7] Turk C, Turk S, Malkan UY, Haznedaroglu IC. Three critical clinicobiological phases of the human SARS-associated coronavirus infections. Eur Rev Med Pharmacol Sci. 2020; 24: 8606-8620. [CrossRef]

[8] Li L, Yang Z, Dang Z, Meng C, Huang J, Meng H, et al. Propagation analysis and prediction of the COVID-19. Infect Dis Model. 2020; 5: 282-292. [CrossRef]

[9] Huang C, Wang Y, Li X, Ren L, Zhao J, Hu Y, et al. Clinical features of patients infected with 2019 novel coronavirus in Wuhan, China. Lancet. 2020; 395: 497-506. [CrossRef]

[10] Singhal T. A Review of Coronavirus Disease-2019 (COVID-19). Indian J Pediatr. 2020; 87: 281-6. [CrossRef]

[11] Rothe C, Schunk M, Sothmann P, Bretzel G, Froeschl G, Wallrauch C, et al. Transmission of 2019-nCoV Infection from an Asymptomatic Contact in Germany. N Engl J Med. 2020; 382: 970-971. [CrossRef]

[12] Peng X, Xu X, Li Y, Cheng L, Zhou X, Ren B. Transmission routes of 2019-nCoV and controls in dental practice. Int J Oral Sci. 2020; 12. [CrossRef]

[13] Guan W, Ni Z, Hu Y, Liang W, Ou C, He J, et al. Clinical Characteristics of Coronavirus Disease 2019 in China. N Engl J Med. 2020; 382: 1708-1720. [CrossRef]

[14] Bekdas M, Goksugur S, Sarac E, Erkocoglu M, Demircioglu F. Neutrophil/lymphocyte and C-reactive protein/mean platelet volume ratios in differentiating between viral and bacterial pneumonias and diagnosing early complications in children. Saudi Med J. 2014; 35: 442-447.

[15] Terpos E, Ntanasis-Stathopoulos I, Elalamy I, Kastritis E, Sergentanis TN, Politou M, et al. Hematological findings and complications of COVID-19. Am J Hematol. 2020; 95: 834-47. [CrossRef]

[16] Zhou F, Yu T, Du R, Fan G, Liu Y, Liu Z, et al. Clinical course and risk factors for mortality of adult inpatients with COVID-19 in Wuhan, China: a retrospective cohort study. Lancet. 2020; 395: 1054-1062. [CrossRef]

[17] Fogarty H, Townsend L, Ni Cheallaigh C, Bergin C, Martin-Loeches I, Browne P, et al. COVID19 coagulopathy in Caucasian patients. Br J Haematol. 2020; 189: 1044-1049. [CrossRef]

[18] Liao D, Zhou F, Luo L, Xu M, Wang H, Xia J, et al. Haematological characteristics and risk factors in the classification and prognosis evaluation of COVID-19: a retrospective cohort study. Lancet Haematol 2020; 7: e671-8. [CrossRef]

[19] Yuan X, Huang W, Ye B, Chen C, Huang R, Wu F, et al. Changes of hematological and immunological parameters in COVID-19 patients. Int J Hematol. 2020; 112: 553-559. [CrossRef]

[20] Elshazli RM, Toraih EA, Elgaml A, El-Mowafy M, El-Mesery M, Amin MN, et al. Diagnostic and prognostic value of hematological and immunological markers in COVID-19 infection: A meta-analysis of 6320 patients. PLoS One. 2020; 15: e0238160. [CrossRef]

[21] Wrapp D, Wang N, Corbett KS, Goldsmith JA, Hsieh C-L, Abiona O, et al. Cryo-EM Structure of the 2019-nCoV Spike in the Prefusion Conformation. Science. 2020; 367. [CrossRef]

[22] Wang D, Hu B, Hu C, Zhu F, Liu X, Zhang J, et al. Clinical characteristics of 138 hospitalized patients with 2019 novel coronavirus-infected pneumonia in Wuhan, China. JAMA - J Am Med Assoc. 2020; 323: 1061-1069. [CrossRef]

[23] Djakpo DK, Wang Z, Zhang R, Chen X, Chen P, Ketisha Antoine MML. Blood routine test in mild and common 2019 coronavirus (COVID-19) patients. Biosci Rep. 2020; 40. [CrossRef]

[24] Algassim AA, Elghazaly AA, Alnahdi AS, Mohammed-Rahim OM, Alanazi AG, Aldhuwayhi NA, et al. Prognostic significance of hemoglobin level and autoimmune hemolytic anemia in SARS-CoV-2 infection. Ann Hematol. 2020: 1-7. [CrossRef]

[25] Bassetti M, Vena A, Giacobbe DR. The novel Chinese coronavirus (2019-nCoV) infections: Challenges for fighting the storm. Eur J Clin Invest. 2020; 50. [CrossRef] 
[26] Amgalan A, Othman M. Exploring possible mechanisms for COVID-19 induced thrombocytopenia: Unanswered questions. J Thromb Haemost. 2020; 18: 1514-1516. [CrossRef]

[27] Diagnosis and Treatment Protocol for Novel Coronavirus Pneumonia (Trial Version 7). Chin Med J (Engl). 2020; 133: 1087-1095. [CrossRef]

[28] Chen G, Wu D, Guo W, Cao Y, Huang D, Wang H, et al. Clinical and immunological features of severe and moderate coronavirus disease 2019. J Clin Invest. 2020; 130: 2620-2629. [CrossRef]

[29] Van Der Poll T, Van De Veerdonk FL, Scicluna BP, Netea MG. The immunopathology of sepsis and potential therapeutic targets. Nat Rev Immunol. 2017; 17: 407-420. [CrossRef]

[30] Al-Tawfiq JA, Hinedi K, Abbasi S, Babiker M, Sunji A, Eltigani M. Hematologic, hepatic, and renal function changes in hospitalized patients with Middle East respiratory syndrome coronavirus. Int J Lab Hematol. 2017; 39: $272-278$. [CrossRef]

[31] Rabaan Ali A, Al-Ahmed Shamsah H, Haque Shafiul, Sah Ranjit, Tiwari Ruchi, Malik Yashpal Singh, et al. SARSCoV-2, SARS-CoV, and MERS-COV: A comparative overview. Le Infez Med. 2020; 28: 174-84.

[32] Panesar NS. What caused lymphopenia in SARS and how reliable is the lymphokine status in glucocorticoid-treated patients? Med Hypotheses. 2008; 71: 298-301. [CrossRef]

[33] He Z, Zhao C, Dong Q, Zhuang H, Song S, Peng G, et al. Effects of severe acute respiratory syndrome (SARS) coronavirus infection on peripheral blood lymphocytes and their subsets. Int J Infect Dis 2005; 9: 323-330. [CrossRef]

[34] Chu H, Zhou J, Wong BHY, Li C, Chan JFW, Cheng ZS, et al. Middle East Respiratory Syndrome Coronavirus Efficiently Infects Human Primary T Lymphocytes and Activates the Extrinsic and Intrinsic Apoptosis Pathways. J Infect Dis 2016; 213: 904-914. [CrossRef]

[35] Tang N, Li D, Wang X, Sun Z. Abnormal coagulation parameters are associated with poor prognosis in patients with novel coronavirus pneumonia. J Thromb Haemost. 2020; 18: 844-547. [CrossRef]

[36] Staubli SM, Schäfer J, Rosenthal R, Zeindler J, Oertli D, Nebiker CA. The role of CRP and Pentraxin 3 in the prediction of systemic inflammatory response syndrome and death in acute pancreatitis. Sci Rep. 2019; 9. [CrossRef]

[37] Pepys MB, Hirschfield GM. C-reactive protein: a critical update. J Clin Invest 2003; 111: 1805-1812. [CrossRef]

[38] Zhao K, Li R, Wu X, Zhao Y, Wang T, Zheng Z, et al. Clinical features in 52 patients with COVID-19 who have increased leukocyte count: a retrospective analysis. Eur J Clin Microbiol Infect Dis. 2020: 1-9. [CrossRef]

[39] Mokart D, Merlin M, Sannini A, Brun JP, Delpero JR, Houvenaeghel G, et al. Procalcitonin, interleukin 6 and systemic inflammatory response syndrome (SIRS): Early markers of postoperative sepsis after major surgery. Br J Anaesth. 2005; 94: 767-773. [CrossRef]

[40] Oda S, Hirasawa H, Shiga H, Nakanishi K, Matsuda KI, Nakamua M. Sequential measurement of IL-6 blood levels in patients with systemic inflammatory response syndrome (SIRS)/sepsis. Cytokine. 2005; 29: 169-175. [CrossRef]

[41] Khalil U, Seliem F, Alnahal A, Awad M, Sadek AE., Fawzy M. Association of serum ferritin with insulin resistance in offsprings of type 2 diabetics. Egypt J Intern Med. 2018; 30: 13. [CrossRef]

[42] IFCC. IFCC information guide on COVID-19 2020.

[43] Cheng Y, Luo R, Wang K, Zhang M, Wang Z, Dong L, et al. Kidney disease is associated with in-hospital death of patients with COVID-19. Kidney Int. 2020; 97: 829-838. [CrossRef]

[44] Naicker S, Yang CW, Hwang SJ, Liu BC, Chen JH, Jha V. The Novel Coronavirus 2019 epidemic and kidneys. Kidney Int. 2020; 97: 824-828. [CrossRef] 